\title{
RELATIVE BOUNDEDNESS-COMPACTNESS INEQUALITIES FOR A SECOND ORDER DIFFERENTIAL OPERATOR
}

\author{
Don B. Hinton And SuZAnne Collier Melescue
}

\begin{abstract}
For a one-term second order differential operator with power coefficients and in the limit circle case, we give necessary and sufficient conditions for perturbations to be relatively bounded or relatively compact. These conditions are expressed in terms of integrals of the coefficients of the perturbing operators and are easily verified in many cases. An application is given to the energy operator of the hydrogen atom.
\end{abstract}

Mathematics subject classification (2000): 26D10, 47A55, 34L05, 34A40.

Key words and phrases: Sturm-Liouville operator; perturbation theory; relatively bounded; relatively compact; maximal and minimal operators.

\section{REFERENCES}

[1] T. G. ANDERSON, R. C. Brown, AND D. B. Hinton, Perturbation Theory for a One-Term Weighted Differential Operator, Spectral Theory and Computational Methods of Sturm-Liouville Problems, Marcel Dekker, Inc., New York, 1997, 149-170.

[2] T. G. ANDERSON AND D. B. HINTON, Relative Boundedness and Compactness Theory for Second Order Differential Operators, J. of Ineq. \& Appl. 1 (1997), 375-400.

[3] F. V. AtKinson, Discrete and Continuous Boundary Problems, Academic Press, New York, 1964.

[4] R. C. BRown, AND D. B. Hinton, Sufficient Conditions for Weighted Inequalities of Sum Form, J. Math. Anal. Appl. 112 (1985), 563-578.

[5] S. C. Melescue, A Theory on Perturbations of the Dirac Operator, J. of Ineq. \& Appl., 4 (1999), 17-56

[6] M. A. NAIMARK, Linear Differential Operators, Part II, Ungar, New York, 1968.

[7] B. OpIC AND A. KufNer, Hardy-type Inequalities, Longman Scientific and Technical Harlow, Essex, UK, 1990.

[8] J. WeIDmann, Spectral Theory of Ordinary Differential Operators, Lecture Notes in Mathematics, Vol 1258, Springer-Verlag, Berlin, 1987. 